\title{
THE IMPACT OF POLLUTION WITH (VOCS) AND (BTEX) ON THE ENVIRONMENT (WATER, SEDIMENT, BIOTA) OF THE OLT RIVER
}

\author{
Mihaela lordache ${ }^{1}$, Luisa Roxana Popescu ${ }^{1}$, Luoana Florentina Pascu², Ioan lordache ${ }^{3}$ \\ ${ }^{1}$ National Research and Development Institute for Industrial Ecology - Ramnicu \\ Valcea Subsidiary, 1 Uzinei Street 240050, Romania, E-mail: \\ mihaelaz1976@yahoo.co.uk \\ ${ }^{2}$ National Research and Development Institute for Industrial Ecology - Bucharest, \\ 71-73 Podu Dambovitei Street, 060650,Bucharest, Romania, ecoind@ \\ incdecoind.ro \\ ${ }^{3}$ National Research and Development Institute for Cryogenics and Isotopic \\ Technologies-ICIT, 4 Uzinei Street, 240050 Rm. Valcea, Romania, E-mail: \\ ioan.iordache@icsi.ro
}

\begin{abstract}
The purpose of this paper is to assess the degree of pollution with volatile organic compounds (VOCs) and volatile aromatic hydrocarbons (BTEX) in water, sediment, biota in lessening the environmental risk. The mathematical model MacKay was performed for volatile organic compounds (dichloromethane, trichlorethylene, and perchlorethylene) and volatile aromatic hydrocarbons (benzene, toluene, ethylbenzene) and as a study areas were chosen sections Cremenari, Babeni-Marcea, Zavideni, Dragasani and Strejesti on the Olt River. The modeling revealed the tendency of transfer to section "air" a dichloromethane, trichloroethylene, benzene, toluene and ethylbenzene, are known that are volatile. However, based on modeling is observed a significant transfer of pollutant perchlorethylene in section "biota" in amounts that can generate medium to long term by taking over risks to human health in the food chain. The modeling has achieved its purpose, providing rapid and with a number of primary values low "fingerprint of pollution" in the accumulation lakes Babeni-Marcea, Zavideni, Dragasani and Strejesti, that indices conclusive risk assessment of rapid which underpin the conclusions on actions / preventive actions for future study area.
\end{abstract}

Keywords: model MacKay, pollution, volatile organic compounds, volatile aromatic hydrocarbons

\section{Introduction}

Protection of water quality is a complex and difficult matter that requires a vast program to collect data on the physical, chemical and biological characteristics of rivers and lakes. Permanent knowledge of the current status, trends evolutionary quality of watercourses is essential for adopting fundamental decisions and is necessary to analyze increasingly closer to their quality. Water is an important factor in the environmental balances and its pollution is a current issue with consequences more or less serious for the population. By water pollution, means altering the physical, chemical and biological characteristics of water, made directly or indirectly by human activities and that makes the waters become unfit for normal purposes where such use 
was possible before the alteration occurred. Effects of pollution of water resources are complex and varied, depending on the nature and concentrations of particulates

One way to estimate the level of pollution with hazardous chemicals to environmental water, sediment, biota is Model MacKay [1]. This model can give hints conclusive for a rapid risk assessment on which to base conclusions on the preventive measures for the future studied area. Effective management requires understanding of the environment and the ability to analyse quantitative risk transfer mechanism associated health and chemical contamination. The level of contamination resulting from accidental chemical discharges or continuous was usually assessed using transfer models on environmental compartments. These models are mainly based on a single environmental compartment, such as the transfer of a contaminant in water. However, the chemicals that are released into the environment, succeed through various compartments of the environment as a result of complex processes physico - chemical and biological [2 -7]. One such model is the MacKay model [8-9], which uses patterned backgrounds to explore the possible behaviour of the chemical. For this purpose model generates some equations that can be validated using real environments. A somewhat different assembly equation proves to be convenient for real-world environments, but the basic principles are the same. Mackay model Level I is based on four basic components: air, water, sediment, soil and to, through bio-concentration factors can be added and biota. This calculation model is based on using its fugacity and can quickly estimate the level of pollution in the environment with pollutants analysed without carrying out analytical determinations costly in terms of time and money [10]. The purpose of this paper is to assess the degree of pollution with volatile organic compounds (VOCs) and volatile aromatic hydrocarbons (BTEX) in water, sediment, biota in lessening the environmental risk.

\section{Materials and Methods (or Experimental)}

\section{General data regarding the fugacity concept}

According to G.N. Lewis, fugacity concept describes the tendency of a chemical transition from one phase to another when they are in contact. It is identical to the concept of ideal gas partial pressure and chemical potential is related to logarithmically, so it varies linearly or non-linearly with concentration. At low partial pressures ideal conditions fugacity is equal to the partial pressure [10].

Based on the concept of fugacity, one can postulate a nearly linear relationship between fugacity dependence and concentration of the chemical in each environmental compartment (eq.1) [8]:

$$
C=Z f
$$

Where $Z$ is a constant of proportionality called "fugacity capacity" with the units mol / $\mathrm{m}^{3} \mathrm{~Pa}$. This equation implies that $C$ always varies linearly with $\mathrm{f}$. Nonlinearity can be adapted by consideration of $Z$ as a function of $C$ or $f$. 
Table 1. Defining the fugacity capacities $[1,8,10]$

\begin{tabular}{|c|c|}
\hline Compartment & Definition Z (mol//m $\left.{ }^{3} \mathrm{~Pa}\right)$ \\
\hline Air & 1/RT ; R=8,314 Pa m³/mol K ; T=Temp (K) \\
\hline Water & $\begin{array}{l}1 / \mathrm{H} \text { sau } \mathrm{C}^{\mathrm{S}} / \mathrm{P}^{S} \\
\mathrm{C}^{\mathrm{S}}=\text { aqueous solubility }\left(\mathrm{mol} / \mathrm{m}^{3}\right) \\
\mathrm{P}^{\mathrm{S}}=\text { vapor pressure }(\mathrm{Pa}) \\
\mathrm{H}=\text { Henry law constant }\left(\mathrm{Pa} \mathrm{m} \mathrm{m}^{3} / \mathrm{mol}\right)\end{array}$ \\
\hline $\begin{array}{l}\text { Solid sorbent (e.g.: } \\
\text { particulate) }\end{array}$ & $\begin{array}{l}K_{P} \rho_{S} / H \quad K_{P}=\text { partition coefficient }(\mathrm{L} / \mathrm{kg}) \\
\rho_{S}=\text { density }(\mathrm{kg} / \mathrm{L})\end{array}$ \\
\hline Biota & $\begin{array}{l}\mathrm{K}_{\mathrm{B}} \rho_{\mathrm{B}} / \mathrm{H} \quad \mathrm{K}_{\mathrm{B}}=\text { bioconcentration factor }(\mathrm{L} / \mathrm{kg}) \\
\rho_{\mathrm{B}}=\text { density }(\mathrm{kg} / \mathrm{L})\end{array}$ \\
\hline Pure solute & $1 / \mathrm{P}^{\mathrm{S}} \mathrm{v} ; \mathrm{v}=$ the molar volume of solute $\left(\mathrm{m}^{3} / \mathrm{mol}\right)$ \\
\hline
\end{tabular}

\section{Areas studied}

In order to study the transfer of volatile organic compounds (VOCs) and volatile aromatic hydrocarbons (BTEX) in the environmental compartments (water, sediment, biota), study areas were chosen sections Cremenari, Babeni-Marcea, Zavideni, Dragasani and Strejesti on the Olt River. In this study, sections studied are located downstream from the chemical platform Ramnicu Valcea. Cremenari section is situated at approx. 8-10 km from industrial platform, while section Babeni-Marcea is located approx. $12 \mathrm{~km}$ from Cremenari section, Zavideni section is located approx. 20 $\mathrm{km}$ to the Babeni-Marcea section, Dragasani section situate approx. $20 \mathrm{~km}$ to the Zavideni section while the Strejesti section is located approx. $10 \mathrm{~km}$ to the Dragasani section.

\section{Results and Discussion}

The mathematical model was developed for analysis of volatile organic compounds (dichloromethane, trichlorethylene, and perchlorethylene) and volatile aromatic hydrocarbons (benzene, toluene, ethylbenzene)). In order to compare the results of the modelling, we used the experimental values presented in Tables 2 and 3. The values of the modelling are presented in Fig. 1 - 6 . Starting from the measured values for these pollutants in environmental factor "water" was achieved transfer of these hazardous pollutants modelling environments "sediment", "biota" and "air". To validate this model were considered values obtained for "sediment", as these types of evidence have been worked. The following are presented point for each sampling point was studied, the results and conclusions highlighted. Biota are approximate quantity of 1 part $/ \mathrm{m}^{3}=7.83 \times 1$ million $107 / 106=78.3[1]$. 
Table 2. The content of (VOCs) and (BTEX) in water of the Cremenari (C), Marcea (M), Zavideni (Z), Dragasani (D) and Strejesti (S) accumulation lakes, $(\mu \mathrm{g} / \mathrm{L})$

\begin{tabular}{|c|c|c|c|c|c|c|c|}
\hline \multirow{2}{*}{$\begin{array}{c}\text { Sample } \\
\text { designation }\end{array}$} & \multirow{2}{*}{$\begin{array}{c}\text { The } \\
\text { period }\end{array}$} & \multicolumn{6}{|c|}{ Quality indicators analysed } \\
\hline & & DCM & 1,1,2-TCE & PCE & Benzene & Toluene & Ethylbenzen \\
\hline C & \multirow{5}{*}{$\begin{array}{c}\text { October } \\
2015\end{array}$} & 11.72 & 1.36 & 2.36 & $<0.025^{\star}$ & $<0.025^{\star}$ & $<0.025^{*}$ \\
\hline M & & 11.38 & 1.6 & 4.63 & $<0.025^{\star}$ & $<0.025^{\star}$ & $<0.025^{\star}$ \\
\hline $\mathbf{Z}$ & & $<0.05^{\star}$ & 0.5 & 0.5 & $<0.025^{\star}$ & $<0.025^{*}$ & $<0.025^{*}$ \\
\hline D & & 10.86 & 1.56 & 3.9 & $<0.025^{*}$ & $<0.025^{*}$ & $<0.025^{*}$ \\
\hline $\mathbf{S}$ & & $<0.05^{*}$ & 0.48 & 0.47 & $<0.025^{\star}$ & $<0.025^{\star}$ & $<0.025^{\star}$ \\
\hline
\end{tabular}

* The determination limit of the method

Table 3. The content of (VOCs) and (BTEX) in water of the Cremenari (C), Marcea (M), Zavideni (Z), Dragasani (D) and Strejesti (S) accumulation lakes, (mg/kg D.W.)

\begin{tabular}{|c|c|c|c|c|c|c|c|}
\hline \multirow{2}{*}{$\begin{array}{c}\text { Sample } \\
\text { designation }\end{array}$} & \multirow{2}{*}{$\begin{array}{c}\text { The } \\
\text { period }\end{array}$} & \multicolumn{6}{|c|}{ Quality indicators analysed } \\
\hline & & DCM & $\begin{array}{l}1,1,2- \\
\text { TCE }\end{array}$ & PCE & Benzene & Toluene & Ethylbenzen \\
\hline$C$ & \multirow{5}{*}{$\begin{array}{c}\text { October } \\
2015\end{array}$} & 10.0 & 2.17 & 4.32 & $<0.01^{*}$ & $<0.01^{*}$ & $<0.01^{*}$ \\
\hline M & & 9.64 & 1.6 & 4.36 & $<0.01^{*}$ & $<0.01^{*}$ & $<0.01^{*}$ \\
\hline $\mathbf{Z}$ & & 12.63 & 1.76 & 5.14 & $<0.01^{*}$ & $<0.01^{*}$ & $<0.01^{*}$ \\
\hline D & & 9.87 & 1.42 & 3.56 & $<0.01^{*}$ & $<0.01^{*}$ & $<0.01^{*}$ \\
\hline $\mathbf{S}$ & & 9.44 & 1.64 & 5.2 & $<0.01^{*}$ & $<0.01^{*}$ & $<0.01^{*}$ \\
\hline
\end{tabular}

* The determination limit of the method

Transfer of dichloromethane

The values obtained for the environmental "sediment" in the modeling of water transfer of dichloromethane are slightly smaller than the experimentally determined. From the modelled values was observed tendency by transfer of this pollutant in the section "Air", with values between $5.468-1244.44 \mathrm{ng} / \mathrm{m}^{3}$, but observed that a large amount is taken from the „biota” compartment, with values between 0.043 to $10.0 \mathrm{mg} / \mathrm{kg}$.

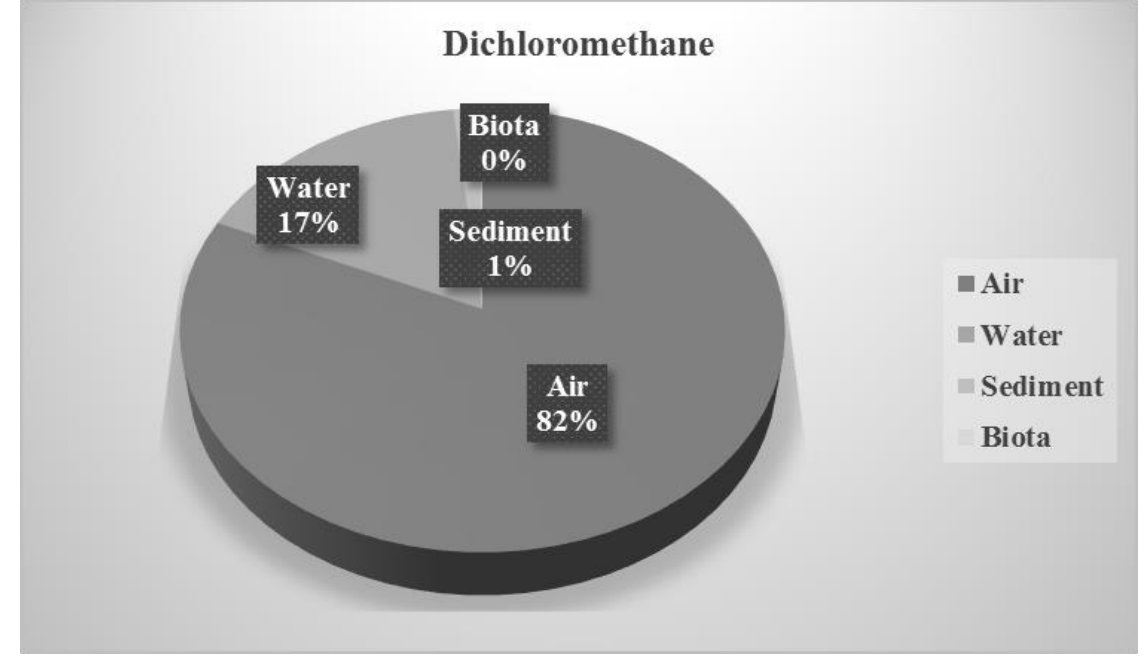


Fig. 1 The transfer of dichloromethane in the environmental air, water, sediment, biota

\section{Transfer of trichloroethylene}

The values obtained for the environmental "sediment" in the modeling of water transfer of trichloroethylene, are very close by to the experimentally determined. Since there is a tendency modeled values of this pollutant transfer in the section "air", with values between $479.15-1,597.15 \mathrm{ng} / \mathrm{m}^{3}$, but observed that a large amount is taken from the "biota" compartment, with values between 6.06 to $20.2 \mathrm{mg} / \mathrm{kg}$, which matched the degree of toxicity of this compound and should be a warning about the level of environmental pollution in the area.



Fig. 2 The transfer of trichloroethylene in the environmental air, water, sediment, biota

Transfer of perchlorethylene

The values obtained for the environmental "sediment" in the modeling of water transfer perchlorethylene are close by to the experimentally determined. From the modeled values is observed that a large amount is taken from the "biota" compartment, with values between $10.55 \mathrm{mg} / \mathrm{kg}$ (Strejesti) -103.95 mg / kg (Marcea), which corroborated the grade the toxicity of this compound and should be a warning about the level of environmental pollution in the area.



Fig. 3 The transfer of perchlorethylene in the environmental air, water, sediment, biota 


\section{Transfer of benzene}

The values obtained for the environmental "sediment" in the modeling of benzene from the water transfer are close to the experimentally determined value of $0.023 \mathrm{mg} / \mathrm{kg}$ to $<0.01 \mathrm{mg} / \mathrm{kg}$ (the limit of detecrmination of the method), in all sections analyzed . It is observed that the tendency transfer pollutant in the section "air" (6.6 ng / m3), but is also observed that a large quantity is taken from the section "biota", $0.151 \mathrm{mg} / \mathrm{kg}$.

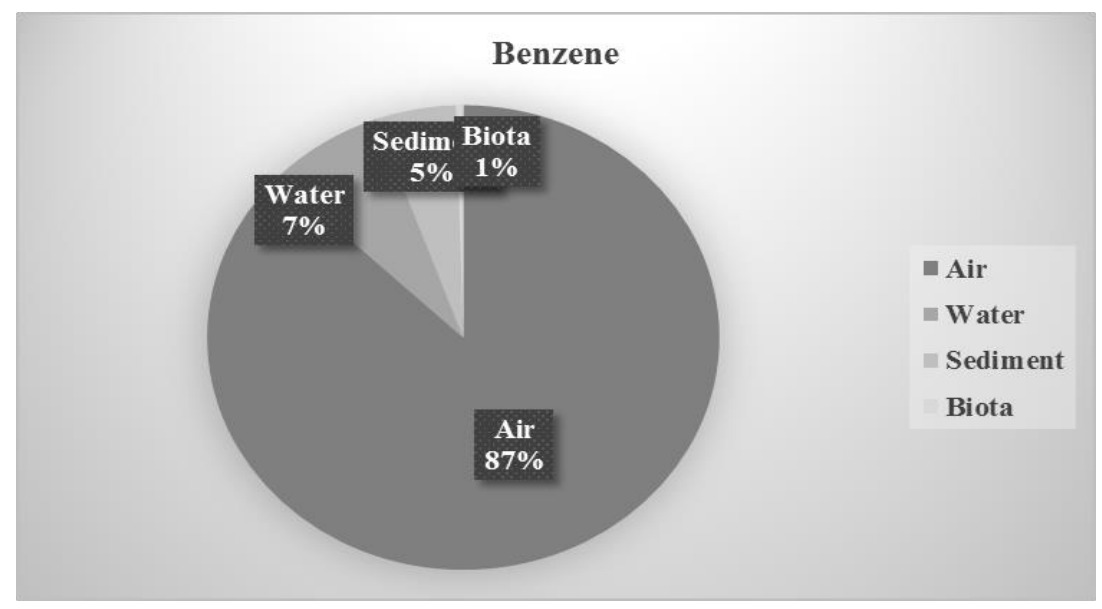

Fig. 4 The transfer of benzene in the environmental air, water, sediment, biota

\section{Transfer of toluene}

The values obtained for the environmental "sediment" in the modeling of the toluene the water transfer are close to the experimentally determined value of $0.129 \mathrm{mg} / \mathrm{kg}$ to $<0.01 \mathrm{mg} / \mathrm{kg}$ (the limit of determination of the method), in all sections analyzed. From there is a tendency modeled values of this pollutant transfer in the section "air" (8.2 ng $/ \mathrm{m}^{3}$ ), but observed that a large amount is taken from the "biota" compartment, 0.675 $\mathrm{mg} / \mathrm{kg}$.



Fig. 5 The transfer of toluene in the environmental air, water, sediment, biota 


\section{Transfer of ethylenbenzene}

The values obtained for the environmental "sediment" in modeling the transfer of water ethylbenzene are close to the experimentally determined value of $3.317 \mathrm{mg} / \mathrm{kg}$ to $<0.01 \mathrm{mg} / \mathrm{kg}$ (the limit of determination of the method), in all analyzed sections. From the modeled values, there is a tendency of this pollutant transfer in the section "air" $(9.3 \mathrm{ng} / \mathrm{m} 3)$, but observed that a large amount is taken from the "biota" compartment, $1.66 \mathrm{mg} / \mathrm{kg}$.

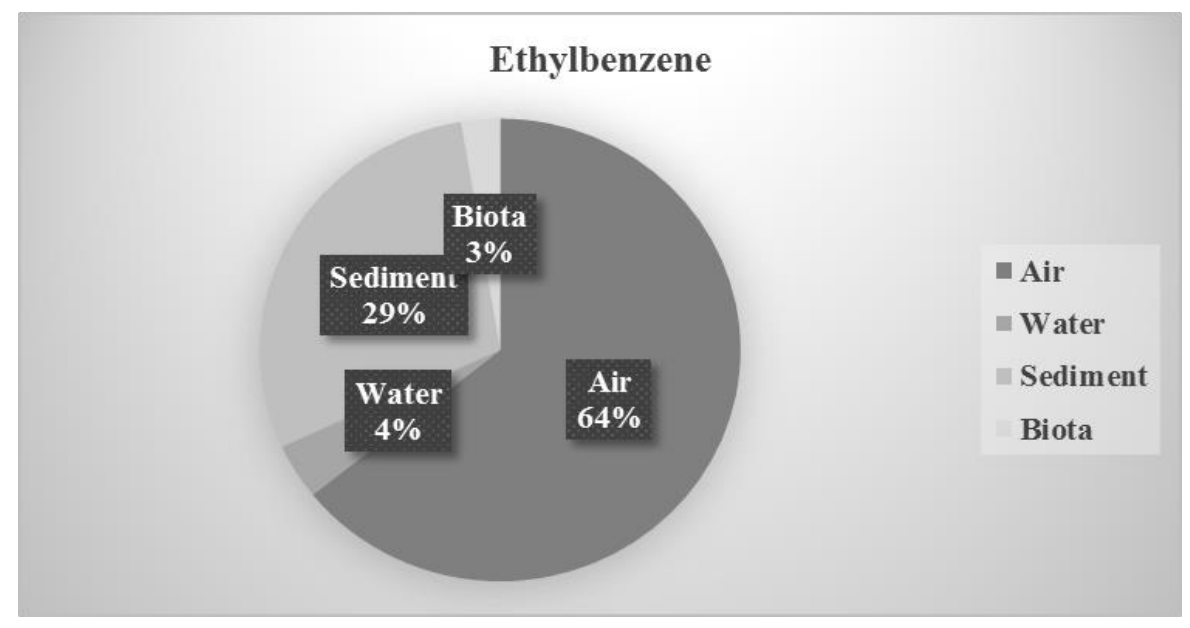

Fig. 6 The transfer of ethylbenzene in the environmental air, water, sediment, biota

\section{Conclusions}

After analyzing the results of modeling the studied compounds, it can be concluded that the model based on "fugacity" applied, generated realistic indicative targets for environmental compartments of interest, air, sediment, biota. Modeled valuesobtained for section "sediment" are comparable and compatible with the valuesobtained by analytical measurements, which provides rapid indication of the level of pollutant pollution that environmental compartment studied. Modelling revealed the trend of transfer compartment "air" of dichloromethane, trichlorethylene, benzene, toluene and ethylbenzene, known because they are volatile. However, based on modeling observed a significant transfer of pollutant perchlorethylene in section "biota" in amounts that can generate medium and long term risk to human health by taking in the food chain, which at first sight and a first risk assessment made by these pollutants for residents, may go unnoticed.

\section{Acknowledgements}

The authors acknowledge the financial support from the Ministry of Education - State Authority for Research Scientific, technological development and innovation through the Proiect PN 09-13 02 23, "Research concerning the influence of organochlorine substance the environment (water, sediment, and biota)". 


\section{References}

[1] lordache M., Popescu L. R., Pascu L. F., Neamtu S., Iordache I., Assessment of Pollution with Organochlorine Substances in the Accumulation Lakes on the Olt River, Using the Fugacity Model, REV.CHIM.(Bucharest), 67, No. 6, 2016, 1186 - 1190.

[2] Warren C., Mackay D., Whelan M., Fox K., Chemosphere 61, 2005, p. 1458 - 1467.

[3] Luo Y., Gao Q., Yang X., Journal of Environmental Management 83, 2007, p. 44 - 55.

[4] Gokgoz-Kilic S., Aral M. M., Journal of Environmental Management 88, 2008, p. 448 - 457.

[5] Dong J., Gao H., Wang S., Yao H. \& Ma M., 2009. Simulation of the transfer and fate of HCHs since the 1950s in Lanzhou, China, Ecotoxicology and Environmental Safety, 72, 19501956.

[6] Zhang Yi-Z., Song X.-F., Kondoh A., Xia J. \& Tang C.-Y., 2011, Behavior, mass inventories and modeling evaluation of xenobiotic endocrine-disrupting chemicals along an urban receiving wastewater river in Henan Province, China, Water research 45(1), 292-302.

[7] Luo X., Zheng Yi, Lin Z., Wu B., Han F., Tian Y., Zhang W. \& Wang X., 2015, Evaluating potential non-point source loading of PAHs from contaminated soils: A fugacity-based modeling approach, Environmental Pollution 196, 1-11.

[8] Mackay D. \& Paterson S., 1981. Calculating fugacity, Environmental Science Technology, 15(9), 1006-1014.

[9] Mackay D., 1991. Multimedia Environmental Models. The Fugacity Approach, Lewis Publishers Inc.

[10] Iordache M., Popescu L. R., Pascu L. F., Iordache I., Estimated Transfer of Volatile Organochlorine Substances in the Ecosystems Water, Sediment, Biota Using the Concept of Fugacity, Progress of Cryogenics and Isotopes Separation, 18, issue 1/2015, p. 99-114. 